\title{
CORRECTION
}

\section{ON CHARACTERISTIC FUNCTION-BASED BOOTSTRAP TESTS}

\section{Andrea Pallini}

J. It. Statist. Soc. (1992) 1 pp. 77-86

In the Proof of Theorem 1 the symbol $\cap$ (intersection) was inadvertently omitted, between $\boldsymbol{I B}_{1}$ and $\boldsymbol{B}_{2}$. In equations (10) and (12) symbol $\Sigma$ (sum) has to be substituted with $\Pi$ (product).

Address for correspondence: Andrea Pallini, Laboratorio di Statistica, Facoltà di Economia e Commercio, Università degli Studi di Venezia, Ca' Foscari, Dorsoduro 3246, I-30123, Venezia, Italy. 